\title{
Raúl Prebisch e a concepção e evolução do sistema centro-periferia
}

\author{
Raúl Prebisch and the conception and evolution \\ of the core-periphery system
}

JOAQUIM MIGUEL COUTO*

\begin{abstract}
RESUMO: Este artigo descreve a trajetória profissional de Raúl Prebisch e, ao mesmo tempo, analisa sua contribuição teórica no momento em que buscava decifrar a história e os problemas do desenvolvimento econômico da América Latina. De assessor de ministros a direção do Banco Central Argentino, da CEPAL para a UNCTAD, batalhas não lhe faltaram. Enquanto trilhava suas funções públicas, Prebisch foi interpretando teoricamente o mundo em que vivia. Nasceu, assim, o sistema centro-periferia, que incluía as ideias do crescimento para dentro, a deterioração dos termos de intercâmbio e a luta pela industrialização através da substituição de importações.

PALAVRAS-CHAVE: Prebisch, Raúl; Sistema centro-periferia; CEPAL, UNCTAD.
\end{abstract}

ABSTRACT: This paper describes the career of Raúl Prebisch and, at the same time, analyze his theoretical contribution when he tried to decipher the history and problems of economic development in Latin America. From adviser to ministers to the direction of the Argentine Central Bank, from ECLAC to UNCTAD he faced many battles. While worked in public positions, Prebisch was theoretically interpreting the world in which he lived. Thus emerged the core-periphery system, which included ideas of growth, the deteriorating terms of trade and the struggle for industrialization through import substitution.

KEYWORDS: Prebisch, Raúl; Core-periphery system; ECLAC; UNCTAD.

JEL Classification: B31; B22; O14.

\section{INTRODUÇÃO}

A trajetória profissional do economista argentino Raúl Prebisch (1901-1986) foi repleta de desafios para uma única vida. Ao encerrar uma etapa logo se iniciava outra, ainda mais importante. Os diferentes cargos que ocupou não o impedi-

\footnotetext{
* Professor do Departamento de Economia da Universidade Estadual de Maringá.. E-mail: jmcouto@ uem.br. Submetido: 4/outubro/2012; aprovado: 23/dezembro/2015.
} 
ram de produzir várias obras teóricas consistentes, que entraram para a história do pensamento econômico. Ao contrário, os diversos cargos executivos propiciaram a Prebisch um conhecimento do funcionamento do mundo econômico que, por sua vez, permitiram uma elaboração teórica ajustada com a realidade concreta latino-americana.

Neste sentido, Prebisch foi o principal intérprete das transformações econômicas ocorridas na América Latina a partir da crise mundial do início dos anos 1930. Seu arcabouço teórico original, através do "sistema centro-periferia" (que incluía a "industrialização por substituição de importações”), influenciou o pensamento da nova geração de economistas latino-americanos no limiar da década de 1950. No Brasil, Celso Furtado e Maria da Conceição Tavares, entre outros, utilizaram os instrumentos teóricos criados por Prebisch nas suas interpretações exclusivas do nosso país.

Enquanto no século XIX Simón Bolívar e seus amigos abriram o caminho para a independência política dos países latino-americanos, Raúl Prebisch, no século XX, foi o responsável por libertar estes mesmos países das ideias econômicas oriundas do mundo rico e industrializado da Europa e dos Estados Unidos. A trajetória profissional de Prebisch se mescla com o surgimento da maioria de suas ideias econômicas, tornando difícil dissociar o homem de ação do homem erudito.

Dessa forma, o objetivo deste artigo é descrever a trajetória profissional de Raúl Prebisch e, ao mesmo tempo, analisar sua contribuição teórica no momento em que ele buscava decifrar a história e os problemas do desenvolvimento econômico da América Latina, propondo soluções práticas através de vários textos publicados sob a égide da CEPAL e da UNCTAD. Porém, devido ao limite de tamanho do texto, as ideias de Prebisch não são analisadas de forma mais detalhada.

Para cumprir tal objetivo, o artigo foi dividido em seis seções. Na primeira, é apresentada uma resenha das principais obras que examinam a vida e as ideias de Prebisch. Na segunda seção é descrita sua formação acadêmica, influências intelectuais e os primeiros empregos. A terceira seção trata das ações concretas de Prebisch durante sua passagem pelo governo da Argentina, entre 1930 e 1943. Ainda nesta seção são indicados os primórdios da concepção do sistema centro-periferia. Depois, na quarta seção, são analisados os motivos de sua entrada na Comissão Econômica para a América Latina e o Caribe (CEPAL) e de sua fundamental contribuição teórica que, por sua vez, influenciaria nos objetivos da “Aliança para o Progresso". A quinta seção aborda a ida de Prebisch para a Conferência das Nações Unidas sobre Comércio e Desenvolvimento (UNCTAD) e o seu retorno ao Instituto Latino-Americano de Planejamento Econômico e Social (ILPES). Também nesta seção é explorada a evolução do sistema centro-periferia para além da órbita latino-americana. Por fim, na sexta seção, é analisada a sua contribuição teórica enquanto dirigia a Revista de la CEPAL e a sua última grande missão profissional, como assessor econômico do presidente da Argentina, Raúl Alfonsín. 


\section{A LITERATURA SOBRE PREBISCH}

O primeiro texto que vem à mente quando se pensa nas ideias de Prebisch ou da CEPAL é o livro do uruguaio Octavio Rodríguez, intitulado Teoria do subdesenvolvimento da CEPAL (Rodríguez, 1981). Quase vinte anos depois, Rodríguez publicou outro livro que tratou do pensamento da CEPAL, intitulado O estruturalismo latino-americano, original de 2006, e publicado no Brasil em 2009. Na visão de Rodríguez, as ideais básicas do pensamento estruturalista latino-americano provêm da concepção centro-periferia de Raúl Prebisch (Rodríguez, 2006).

No entanto, antes do surgimento do primeiro livro de Rodríguez, coube a Aníbal Pinto a primazia de reunir as ideias de Prebisch e da CEPAL num único volume. Publicado pela égide da CEPAL, em 1969, El pensamiento de la CEPAL comemorava os vinte anos da criação da Comissão (CEPAL, 1969).

Das publicações que ajudam a entender as ideias de Prebisch e sua carreira profissional, os livros de entrevistas concedidas por ele são fundamentais. O principal livro de entrevistas foi concebido pelo embaixador uruguaio Mateo Magariños. Publicado em 1991, Diálogos con Raúl Prebisch contém gravações feitas em dezembro de 1971, na cidade de Estocolmo (Magariños, 1991). Já Julio González del Solar entrevistou Prebisch, em 1983, e abarcou o seu período de trabalho na Argentina, até o ano de 1948 (Solar, 2005). Outra importante entrevista foi recolhida por David Pollock, em 1985, e publicada em partes ao longo dos anos. A primeira parte foi publicada na revista Desarrollo Económico, em 1991. "Del ortodoxo al conservador ilustrado: Raúl Prebisch en la Argentina, 1923-1943" tratou da vida de Prebisch entre 1923 e 1943 (González e Pollock, 1991). A segunda parte, denominada "Entrevista inédita a Prebisch: logros y deficiencias de la CEPAL", englobou o período 1948-1963 e foi publicada na Revista de la CEPAL (Pollock, Kerner e Love, 2001). A terceira parte apareceu como capítulo de livro editado por Edgar Dosman. O capítulo denominado "Prebisch en la UNCTAD" cobria o período 1964-1969 (Pollock, Kerner e Love, 2006).

Apesar das entrevistas publicadas, a primeira e única biografia de Prebisch foi lançada somente em 2010. Escrita pelo canadense Edgar Dosman, o livro é um trabalho honesto e minucioso da vida, mas também da obra teórica de Prebisch (Dosman, 2010). Menos ambicioso e mais modesto, o livro de Joseph Hodara sobre Prebisch e a CEPAL, de 1987, era até o lançamento do livro de Dosman a melhor contribuição sobre a trajetória profissional de Prebisch (Hodara, 1987).

Dosman também publicou um livro de artigos sobre Prebisch, em 2006, com textos de antigos colaboradores de Raúl, como Enrique Iglesias, Carlos Mallorquín, David Pollock, entre outros (Dosman, 2006).

As ideias de Prebisch, porém, não foram aceitas pelos teóricos da economia neoclássica dos países desenvolvidos. O primeiro trabalho que contestou a teoria centro-periferia de Prebisch (e a necessidade da industrialização para superar o subdesenvolvimento) apareceu no pequeno livro International trade and economic development: lectures delivered at the National University of Brazil, do famoso professor das universidades de Chicago e Princeton, Jacob Viner (Viner, 1952). 
Embora não seja um texto específico sobre as ideias de Prebisch, o pequeno ensaio de Albert Hirschman, intitulado "Ideologies of economic development in Latin America", de 1961, publicado na coletânea Latin American issues, organizado pelo próprio Hirschman, demarcou o pensamento de Prebisch. Neste artigo, Hirschman denominou o primeiro texto de Prebisch na CEPAL como "manifesto" (Hirschman, 1961, p. 13-14), citando inclusive os primeiros parágrafos do estudo "O desenvolvimento econômico da América Latina e alguns de seus principais problemas", de 1949. No entanto, o próprio Prebisch acreditava que o "manifesto" fosse outro texto, o segundo documento escrito por ele para a CEPAL, denominado "Crescimento, desequilíbrio e disparidades: interpretação do processo de desenvolvimento econômico", de 1950, maior e mais completo que o primeiro, e que passou a ser conhecido pelo epíteto de "Informe de 49".

Esta interpretação de Prebisch apareceu no livro de entrevistas que concedeu ao embaixador Mateo Magariños, em 1971. Perguntado se o texto "O desenvolvimento econômico da América Latina e alguns de seus principais problemas" era o "manifesto", Prebisch respondeu: "Não. Esse foi o primeiro trabalho de menos densidade que o outro, que foi o informe do ano 49" (Prebisch apud Magariños, 1991, p. 130). A razão da confusão do próprio autor do estudo, Prebisch, talvez tenha explicação no fato de que o "Informe de 49" foi um texto muito mais divulgado e de maior sucesso que o primeiro.

Um belo e substancioso texto sobre Prebisch e suas ideias foi escrito por Adolfo Gurrieri, denominado "La economia política de Raúl Prebisch". Este texto de cerca de 80 páginas apareceu na Introdução ao livro La obra de Prebisch en la CEPAL, do próprio Gurrieri, e que trouxe uma coletânea de textos de Prebisch, em dois volumes, a partir de seu primeiro trabalho na CEPAL (Gurrieri, 1982).

Dois brasileiros trabalharam diretamente com Prebisch e publicaram suas impressões sobre ele e a CEPAL. Celso Furtado acompanhou Prebisch de perto desde sua chegada à CEPAL, em 1949. Estas lembranças estão registradas no livro $A$ fantasia organizada (Furtado, 1985). Já Fernando Pedrão, chefe de divisão do ILPES, na década de 1960, trabalhou diretamente com Prebisch no final dos anos 1960, depois que ele voltou da UNCTAD para o ILPES. Pedrão publicou o livro O pensamento da CEPAL, em que predominam as ideias da primeira década da instituição (Pedrão, 1988).

Por fim, uma série de artigos publicados na Revista de la CEPAL trataram do pensamento de Prebisch. Carlos Cattaneo escreveu o artigo "Prebisch y las relaciones agricultura-industria" (Cattaneo, 1991). Edgardo Floto tratou de comércio internacional em "El sistema centro-periferia y el intercambio desigual" (Floto, 1989). José Manuel Salazar publicou "El resurgimiento de la integración y el legado de Prebisch" (Salazar, 1993). Em 2001, a Revista de la CEPAL publicou uma série de artigos em homenagem ao centenário de nascimento de Prebisch: Adolfo Gurrieri escreveu "Las ideas del joven Prebisch" (Gurrieri, 2001); Edgar Dosman tratou da questão do Estado em "Los mercados y o Estado en la evolución del 'manifesto' de Prebisch” (Dosman, 2001); Octavio Rodríguez voltou-se sobre as ideias-força, em "Prebisch: actualidad de sus ideas básicas" (Rodríguez, 2001); por 
último, José Antonio Ocampo observou as questões atuais do desenvolvimento sob a ótica de Prebisch, em "Raúl Prebisch y la agenda del desarrollo en los albores del siglo XXI” (Ocampo, 2001).

\section{A FORMAÇÃO E OS PRIMEIROS EMPREGOS ${ }^{1}$}

Raúl Federico Prebisch Linares nasceu na província argentina de Tucumán, em 17 de abril de 1901. Prebisch acreditava que sua vocação de economista surgiu aos doze anos de idade, quando acompanhou seu irmão mais velho a um armazém, em Tucumán: ao pagar a conta, o vendedor disse aos irmãos que não tinha troco. Os meninos perguntaram por quê, e o vendedor disse que era a "crise monetária": "Daí comecei a perguntar o que era a crise monetária. Suponho que nesse momento começou a interessar-me o tema" (Prebisch apud Magariños, 1991, p. 34).

Aos 17 anos (1918), Prebisch ingressou na Faculdade de Ciências Econômicas de Buenos Aires. No segundo ano da Faculdade (julho de 1919), publicou seu primeiro artigo numa revista ("El costo de la vida em Italia"). Este seria o primeiro de uma série de pequenos artigos publicados na Revista de Ciencias Económicas e na Revista de Economia Argentina, entre 1919 e 1920. Já em 1921 e 1922, os artigos crescem de tamanho. O tema principal da maioria desses artigos era a moeda e a inflação. No artigo "Anotaciones sobre nuestro medio circulante", de 1921, Prebisch utiliza, pela primeira vez, os termos "centro" para a capital Buenos Aires e "periferia" para as demais províncias argentinas (Dosman, 2010).

Começou a trabalhar no segundo ano da Faculdade, como ajudante de serviços práticos no Seminário de Investigações da instituição, que lhe deu independência financeira em relação a sua família (Magariños, 1991). Porém, frustrado com a qualidade de ensino da Faculdade, resolveu deixar a instituição antes do término do curso de economia, em 1922, obtendo apenas o diploma de contador (Dosman, 2010).

Recomendado por Dr. Eleodoro Lobos (Diretor da Faculdade), Prebisch foi convidado para fazer um informe para a Sociedade Rural Argentina, instituição das mais fortes do país. Intitulado "Información estadística sobre el comercio de carnes", o texto foi o primeiro estudo profissional de Prebisch. Apontava que os frigoríficos argentinos atuavam como um cartel, pagando preços baixos aos produtores e obtendo lucros expressivos (Gonzalez e Pollock, 1991).

Já em 1923, recebeu uma carta do ministro da Fazenda argentina, Rafael Vegas, pedindo que comparecesse ao seu gabinete. O ministro disse que Prebisch tinha sido indicado pelo diretor da Faculdade (Lobos), e que gostaria que ele visi-

\footnotetext{
${ }^{1}$ As próximas seções estão baseadas, em grande parte, nas longas entrevistas concedidas por Prebisch ao embaixador uruguaio Mateo Magariños, em dezembro de 1971 (Magariños, 1991). Trata-se da melhor fonte de informações para entender a vida e a obra de Prebisch. As informações provindas de outras fontes estão identificadas no texto.
} 
tasse a Austrália e a Nova Zelândia, para conhecer como se aplicava o imposto de renda naqueles países. Prebisch ficou três meses na Austrália e um mês na Nova Zelândia. Aprendeu o sistema de imposto de renda destes dois países, bem como a aplicação da estatística nos estudos demográficos. No entanto, em outubro de 1923, o ministro foi substituído, e Prebisch foi obrigado a retornar.

$\mathrm{Na}$ viagem de volta, conheceu no navio o ministro da Agricultura da Argentina, Tomás Le Breton. O ministro lhe perguntou sobre a reforma agrária na Austrália e Prebisch mostrou seus livros e anotações a respeito. Chegando a Buenos Aires, Prebisch foi trabalhar de assessor do ministro Le Breton, examinando os processos de distribuição fiscal da terra, paralisados a mais de quarenta anos. Prebisch ficou neste serviço durante um ano.

Em março de 1925 (aos 24 anos), foi eleito professor da Faculdade de Ciências Econômicas de Buenos Aires, mesmo não tendo terminado o curso de economia. Como o salário não era muito alto, prestou concurso público e foi aprovado para trabalhar como subdiretor na Direção de Estatística da Nação. Le Breton não gostou da saída de Prebisch do ministério, mas não impediu sua nomeação pelo presidente da República.

Estando na Direção de Estatística, Presbich acompanhou o presidente da Sociedade Rural Argentina, Luis Duhau, em sua visita aos Estados Unidos e ao Canadá. Este presidente da Sociedade Rural, em sua volta à Argentina, foi nomeado diretor do Banco de la Nación Argentina (maior banco do país, de controle estatal), onde criou o Departamento de Investigações Econômicas. Nomeou Prebisch para diretor deste departamento em 1927.

\section{O MINISTÉRIO DA FAZENDA E O BANCO CENTRAL}

Em setembro de 1930, a revolução militar levou o general José Uriburu ao poder. O novo ministro da Fazenda, Enrique Pérez, aceitou a recomendação de Luis Duhau e convidou Prebisch para o cargo de subsecretário do ministério. Tinha então 29 anos. Nesta época, Prebisch ainda era um economista de vertente teórica neoclássica, e acreditava profundamente naquilo que havia estudado e ensinado na Faculdade de Ciências Econômicas.

Segundo o próprio Prebisch, coube a ele comandar a economia argentina durante aquele período da Grande Depressão. Disse que nunca mais teve tanto poder na vida econômica da Argentina quanto naquela época. Despachava todas as noites com o presidente Uriburu, e conquistou sua confiança.

De início, Prebisch aplicou medidas ortodoxas nos campos monetário, fiscal, comercial e cambial. Logo, no entanto, percebeu que a economia não se recuperava com as medidas ortodoxas. Começou, então, a aplicar inovações polêmicas, como o imposto de renda progressivo e o controle de câmbio. Também expandiu o crédito para a indústria e para a agricultura. Aplicou medidas de "substituição de importações" contrariando suas fortes convicções ortodoxas e de livre comércio.

Depois de 18 meses dirigindo a economia argentina, Prebisch deixou o seu 
cargo em março de 1932, por divergências com o novo ministro da Fazenda. Retornou para o Departamento de Investigações Econômicas do Banco de la Nación e a cátedra.

No final de 1932, Prebisch foi convidado pela Liga das Nações para participar como "expert" da Comissão Preparatória da Primeira Conferência Econômica Mundial. A Conferência estava sendo organizada em Genebra, sede da Liga das Nações, para tratar dos graves problemas da Grande Depressão.

De Genebra foi para Londres, em fevereiro de 1933, juntar-se à missão de Júlio Roca (vice-presidente da Argentina), que visava a um acordo comercial bilateral entre a Argentina e a Grã-Bretanha. Prebisch teve uma participação muito ativa neste acordo que ficaria conhecido como Pacto Roca-Runciman, assinado em maio de 1933.

Após o fechamento do Pacto Roca-Runciman, Prebisch se incorporou (como assessor) à missão argentina que foi participar da Conferência Econômica e Monetária Mundial de Londres, que teve início em junho de 1933. Prebisch tinha grandes esperanças nesta Conferência, em razão de uma série de artigos que o já famoso economista John Maynard Keynes publicou no jornal londrino Times ${ }^{2}$. No entanto, Neville Chamberlain, do Tesouro inglês, manteve-se inflexível na chamada ortodoxia econômica, não aceitando as sugestões de Keynes ${ }^{3}$.

Depois da Conferência Mundial, Prebisch voltou ao seu posto no Banco de la Nación. Porém, em agosto de 1933, diante de uma grave crise econômica, o presidente da Argentina, Agustín Justo, realizou uma mudança no seu gabinete. Para o Ministério da Fazenda foi nomeado Federico Pinedo, e Luis Duhau foi para o Ministério da Agricultura. Os dois novos ministros ofereceram a Prebisch a subsecretaria de seus ministérios. Num arranjo inédito, os ministros nomearam Prebisch assessor dos dois ministérios, simultaneamente.

Em fins de 1934, o ministro da Fazenda pediu para que Prebisch preparasse um projeto para a criação de um Banco Central. O projeto de criação do Banco Central foi apresentado pelo ministro Pinedo ao Congresso em março de 1935. O Banco Central de la República Argentina começou a operar no dia 31 de maio de 1935, tendo Raúl Prebisch como seu primeiro diretor-geral, e Ernesto Bosch como

\footnotetext{
${ }^{2}$ Segundo Prebisch, estes artigos intitulados "O caminho para a prosperidade" eram de uma "heresia doutrinária tremenda": "Artigos que tiveram em mim uma enorme influência. Ele preconizava ali uma política expansiva para sair da Grande Depressão mundial [...] Ele passava da ortodoxia a um novo caminho herético [...] Eu creio, à distância, que esses artigos eram muito superiores a teorização que ele fez depois, em seu grande livro" (Prebisch apud Magariños, 1991, p. 100). Prebisch tinha a esperança de que a Conferência respaldasse as ideias de Keynes.

${ }^{3}$ A Conferência Econômica Mundial abriu os olhos de Prebisch para a complexidade das negociações
econômicas intergovernamentais. Segundo Gonzalez \& Pollock (1991, p. 465), "Tudo isto constituiu
uma ducha fria de realidade para este jovem economista, que lhe afirmou a convicção acerca da
necessidade da intervenção do Estado, que havia começado a forjar quando foi subsecretário da Fazenda
em 1931”. Já os artigos de Keynes despertaram seu interesse pelo planejamento econômico. Por
influência de Keynes, Prebisch diz que se converteu a favor de uma política expansiva e não ortodoxa
para fomentar o crescimento econômico de países em crise.
} 
presidente. Com 34 anos Prebisch tinha plenos poderes, porém diz que nada fazia de fundamental sem antes consultar o presidente da instituição.

No comando do Banco Central, Prebisch tratou de implantar medidas para superar a crítica situação cambial provocada pela Grande Depressão. Aplicou medidas keynesianas no combate à recessão de 1938, com uma política monetária anticíclica. Com a eclosão da Segunda Guerra, negociou acordos bilaterais com o Brasil e os Estados Unidos, tendo encontros com os presidentes Vargas e Roosevelt (ambos em 1940). No Relatório Anual do Banco Central, de 1943, Prebisch escrevia sobre o "crescimento para dentro" através da industrialização do país (Dosman, 2010, p. 190).

No entanto, em junho de 1943 ocorreu um novo golpe de Estado na Argentina, promovido pelos militares. Entre os líderes do golpe estava o coronel Juan Perón. Na manhã de 19 de outubro de 1943, antes de sair de casa para o trabalho, Prebisch soube de sua demissão da gerência do Banco Central, através de notícia publicada no jornal La Nación. O presidente do Banco Central, Ernesto Bosch, intercedeu a favor de Prebisch junto ao presidente da República, mas não obteve resultado positivo. De acordo com Prebisch, foi o coronel Perón que forçou a sua demissão da direção do Banco Central. Para Dosman (2001, p. 90), não há dúvida de que "[...] o dia em que foi despedido do Banco Central, foi a experiência mais dolorosa de sua vida".

Assim, depois de muitos anos trabalhando na resolução dos problemas econômicos de seu país, Prebisch teve a ideia de escrever um livro contando sua experiência no governo argentino. Em menos de um mês, em dezembro de 1943, Prebisch havia terminado a primeira versão do livro. Porém, não encontrou nenhum editor disposto a publicar a obra. Intitulado "La moneda y el ritmo de la actividad econômica", o manuscrito encontra-se no Archivo Prebisch em Santiago do Chile. Segundo Dosman (2001), que consultou a obra, neste livro não publicado já se encontravam quase todas as teses principais que iriam aparecer na famosa introdução do Estudio Económico de 1948 da CEPAL, só que abarcando apenas o caso argentino. O sistema centro-periferia foi concebido neste livro não publicado ${ }^{4}$.

Com sua saída do Banco Central, Prebisch reassumiu o cargo de professor na Faculdade de Ciências Econômicas. No início de 1944, entre janeiro e abril, viajou até o México a convite do Banco do México, onde fez uma série de palestras sobre a experiência argentina de Banco Central. Destas conferências, foi publicado, posteriormente o livro La creación del Banco Central y la experiência monetária argentina entre los años 1935-1943 (Prebisch, 1972). Prebisch diz ter voltado com grande entusiasmo à cátedra, em 1944. Tinha alunos brilhantes como Aldo Ferrer

\footnotetext{
${ }^{4} \mathrm{Na}$ opinião de Dosman (2001, p. 94), “O manuscrito é um ponto de referência essencial de seu pensamento nesse ano, ao término de sua carreira no Banco Central, e demonstra que havia elaborado seu conceito de 'desenvolvimento para dentro' muito antes da criação da CEPAL, e que essa elaboração teórica estava mais adiantada do que se imagina”.
} 
e Norberto González. No entanto, no final de 1948, o agora presidente Perón exigiu sua renúncia da Faculdade, deixando a instituição em 15 de novembro.

Não resta dúvida de que foi neste período, entre 1943 e 1948, que Prebisch conseguiu sistematizar suas ideias econômicas. Numa época marcada pela Grande Depressão e com base em sua experiência profissional, Prebisch questionou severamente a validade da teoria econômica neoclássica: voltava a ser professor, mas como ensinar algo que ele mesmo sabia que não funcionava no mundo real? Como explicar aos seus alunos que o livre comércio era benéfico, mas que teve que controlar as importações por falta de divisas internacionais? Como dizer que o câmbio livre ajustava o balanço de pagamentos, sendo ele próprio a pessoa que implantou o controle do câmbio na Argentina, pela simples falta de moeda estrangeira? Como dizer que o Estado não deveria intervir na economia, se o que mais fez como funcionário do governo foi intervir na economia? Como justificar a neutralidade da moeda, se durante a crise econômica ele mesmo expandiu o crédito visando ao crescimento da economia? Como apoiar a divisão internacional do trabalho, dado que os preços dos produtos argentinos se deterioravam em relação às importações de manufaturas? Dessa forma, as medidas econômicas heterodoxas implantadas por Prebisch, quando comandava a economia argentina, lhe afastaram da teoria econômica neoclássica (Magariños, 1991).

Dois artigos publicados em 1944 já demonstravam o desacordo de Prebisch com a teoria dominante. Tanto "Observações sobre os planos monetários internacionais", quanto "O padrão-ouro e a vulnerabilidade econômica de nossos países”, tinham como principal conceito teórico o ciclo econômico. Para Prebisch, o ciclo se manifestava em um movimento alternado de rendas que se contraíam e se dilatavam em um processo circulatório. Este processo circulatório das rendas não se limitava à esfera interna de um país, era pois um fenômeno internacional. Prebisch não aceitava o sistema de equilíbrio dos economistas marginalistas. Tinha a visão de que a realidade era eminentemente cíclica. O ciclo era uma sucessão de desequilíbrios, portanto, incompatível com o equilíbrio geral (Prebisch, 1944a, 1944b). Segundo Gurrieri (1982), foi através da análise dos ciclos e da dinâmica econômica que Prebisch começou a assentar as bases de sua teoria do desenvolvimento econômico, o chamado "sistema centro-periferia" 5

Dificilmente Prebisch conseguiria transpor as ideias econômicas neoclássicas

\footnotetext{
${ }^{5}$ Sobre o sistema centro-periferia, este aparece de forma clara em 1946 ("Memoria de la Primeira Reunión de Técnicos sobre Problemas de Banca Central del Continente Americano”, publicado pelo Banco do México): “Os Estados Unidos, a meu ver, desempenham ativamente o papel de centro cíclico principal, não só no continente, mas em todo o mundo; e os países latino-americanos estão na periferia do sistema econômico [...] Por que chamo os Estados Unidos de centro cíclico? Porque deste país, em função da sua magnitude e de suas características, partem os impulsos de expansão e contração na vida econômica mundial e especialmente na periferia latino-americana, cujos países estão sujeitos às influências destes impulsos, como haviam estado anteriormente, quando a Grã-Bretanha tinha o papel de centro cíclico principal [...] Eu creio que o movimento cíclico é universal, que há um só movimento que vai se propagando de país a país. Portanto, não se deveria dividir o processo em várias partes independentes; não há um ciclo nos Estados Unidos e um ciclo em cada um dos países da periferia. Tudo
} 
se não tivesse tomado contato com a nova teoria econômica formulada por Keynes. Para Prebisch, os artigos de Keynes de 1933 eram muito mais audaciosos que o seu grande livro de 1936. Porém, foi na Teoria Geral que Keynes, segundo Prebisch, formulou uma teoria que justificava a prática econômica de vários países durante a Grande Depressão: obras públicas, expansão monetária, protecionismo e a forte intervenção do Estado (que inclusive deveria "socializar os investimentos"). Prebisch se agarrou tanto nos ensinamentos de Keynes, que publicou uma série de artigos explicando o livro revolucionário. Agrupados, foram publicados com o título de "Introdução a Keynes" (Prebisch, 1947).

No entanto, é preciso esclarecer que para Prebisch $(1949,1950)$ o grande problema dos países latino-americanos durante a Grande Depressão foi a falta de moeda estrangeira (desequilíbrio externo), enquanto na visão de Keynes o principal problema dos países industrializados era a "insuficiência da demanda efetiva" (Keynes, 1936, p. 33).

Pode-se considerar que este é um período formativo das ideias de Prebisch sobre o desenvolvimento econômico, e que só viriam a constituir-se em um todo consistente quando de sua entrada na CEPAL. Assim, concordamos com Rodríguez (1981) que os textos dessa fase são claros antecedentes do sistema centro-periferia.

\section{A CEPAL E A ALIANÇA PARA O PROGRESSO}

Meses antes de ser demitido da Faculdade de Ciências Econômicas, ainda em meados de 1948, Prebisch recebeu a visita do chileno Benjamín Cohen (Subsecretário das Nações Unidas) com a seguinte mensagem do norueguês Trygve Lie (Secretário-Geral da ONU): convidava Prebisch para assumir a Secretária Executiva da CEPAL (Comissão Econômica para a América Latina e o Caribe), com sede em Santiago do Chile. Prebisch recusou o convite por estar muito animado com a cátedra e por não acreditar mais em organizações internacionais (Pollock et al., $2001)^{6}$. Coube ao economista mexicano Martínez Cabañas assumir o posto de Secretário Executivo da CEPAL.

Poucos dias depois de sua demissão da Faculdade, em novembro de 1948, o Diretor-Gerente do Fundo Monetário Internacional (FMI), Camille Gutt, esteve

constitui um só movimento, mas dividido em fases muito distintas com características claramente diferentes, segundo se trate do centro cíclico ou da periferia" (Prebisch apud Rodríguez, 1981, p. 34-35).

${ }^{6}$ A CEPAL havia sido criada em 25 de fevereiro de 1948 pelo Conselho Econômico e Social das Nações Unidas, visando à promoção do desenvolvimento econômico da região, com sede em Santiago do Chile. Sua criação foi fruto da luta do embaixador chileno Hernán Santa Cruz no Conselho Econômico desde julho de 1947 (Cayuela, 1988). A votação de criação da CEPAL no Conselho Econômico da ONU não foi unânime: 13 votos a favor, nenhum contra, mas 4 abstenções (Estados Unidos, Canadá, União Soviética e Bielorrússia). Já se percebia que os Estados Unidos seriam o principal inimigo da Comissão. Celso Furtado foi o primeiro brasileiro a ingressar na CEPAL, em fevereiro de 1949. 
em Buenos Aires e convidou Prebisch para assumir um alto cargo na instituição: assessor do diretor-gerente. Prebisch aceitou. Faltava apenas a aprovação pelo Diretório Executivo do FMI. Mas a aprovação não ocorreu. Em fevereiro de 1949, Gutt se desculpou e disse que o Diretório Executivo havia recusado o seu nome (Dosman, 2001).

Neste mesmo mês de fevereiro de 1949, Martínez Cabañas fez um novo convite a Prebisch: escrever a introdução do primeiro Estudio Económico de la America Latina, como consultor, por um período de três meses. Como havia sido demitido da Faculdade, recusado pelo FMI e vendo-se obrigado a migrar pela ditadura de Perón, Prebisch acabou aceitando a nova proposta da CEPAL. Foi para Santiago no início de março de 1949.

O exílio de Prebisch no Chile (aos 48 anos) se apresentava como o ponto-final de uma carreira de sucesso. Entre 1930 e 1943, Prebisch havia sido um dos principais condutores da economia argentina, com amplo reconhecimento externo. No entanto, as forças que empurraram Prebisch para o Chile nunca imaginariam o que iria acontecer a partir de então. Nem o próprio Prebisch poderia acreditar que o futuro seria para ele maior que o passado. Na CEPAL, suas ideias ganhariam toda a América Latina; e, na UNCTAD, conquistaria uma boa parte do mundo, a ponto de ser indicado para o Prêmio Nobel de Economia. Para Magariños (1991, p. 18), o exílio de Prebisch se converteu no início de sua brilhante carreira internacional: "O que se poderia considerar como um tropeço definitivo de sua carreira, [o exílio] se converteu no lançamento para um futuro resplandecente”.

Segundo Furtado (1985), passado um mês de sua chegada na CEPAL, Prebisch fez circular um texto que logo foi recolhido. Tinha as ideias da industrialização, os desequilíbrios externos e classificava os países em centrais e periféricos, mas a posição era "defensiva". Na véspera da Conferência de Havana da CEPAL, Prebisch apresentou um outro texto. Nas palavras de Furtado (1985, p. 60), "O novo texto de Prebisch não circulou para discussão [...] Tratava-se de um texto mais longo, contendo quadros e gráficos e o tom havia mudado. A linguagem agora era de um manifesto que conclamava os países latino-americanos a engajar-se na industrialização". Este texto, que seria a Introdução do Estudio Económico de 1948, intitulado "O desenvolvimento econômico da América Latina e alguns de seus principais problemas", é considerado a gênese do "pensamento da CEPAL" e a concretização do sistema de relações econômicas internacionais denominado "centro-periferia" .

\footnotetext{
${ }^{7}$ Para Dosman (2001), a mudança entre o primeiro e o segundo texto deveu-se ao artigo de Hans Singer, funcionário das Nações Unidas, intitulado "Post-war price relations between under-developed and industrialized countries". O artigo tratava da deterioração dos preços de intercâmbio que Prebisch já havia exposto no livro não publicado de 1943. Assim, segundo Dosman (2001), quando o texto de Singer chegou às mãos de Prebisch, motivou-o a voltar à sua tese da deterioração dos termos de intercâmbio, e reescrever uma nova Introdução, muito mais ambiciosa e polêmica. Singer (1950) afirmava que a deterioração era causada pela elasticidade-renda da demanda, porém Prebisch creditava esta deterioração tanto à elasticidade-renda quanto ao ciclo econômico. A literatura econômica classificou a teoria da deterioração dos termos de intercâmbio de "Tese Prebisch-Singer".
} 
Em maio de 1949 teve início a segunda Conferência da CEPAL, em Havana. $\mathrm{Na}$ Conferência, Prebisch expôs a sua Introdução aos representantes dos países-membros, que discutia temas como industrialização, relação de preços de intercâmbio e o estrangulamento externo. Para Santa Cruz (1985, p. 36), apesar de suas "ideias estimulantes", o informe de Prebisch não foi objeto de um grande debate, e "Muitos o consideraram apenas como uma especulação teórica, de interesse puramente acadêmico". Ao contrário deste, o futuro Estudio Económico de 1949 teria enorme repercussão.

Presente em Havana, o Subsecretário-Geral da ONU, David Owen, convidou Prebisch para permanecer na CEPAL por mais um ano. Aceitando o convite, Prebisch trabalhou com sua equipe no sentido de dar mais consistência às teses expostas no texto apresentado em Havana. O novo trabalho, intitulado "Crescimento, desequilíbrio e disparidades: interpretação do processo de desenvolvimento econômico", tinha o dobro do tamanho do anterior, e fez parte do primeiro capítulo do Estudio Económico de 1949, apresentado na terceira Conferência da CEPAL, em Montevidéu (maio de 1950). Nas palavras de Prebisch, “[...] os trabalhos que eu apresentava, como esse famoso informe de 49 , foram recebidos como uma coisa notável que abria rumos ao pensamento econômico da América Latina [...] primeiro ampliei o informe [do ano anterior], lhe dei mais volume, mais fundamento, o completei com um grande material estatístico, e depois de um ano de trabalho foi muito bem recebido" (Prebisch apud Magariños, 1991, p. 132) ${ }^{8}$.

Para Furtado (1985), a Conferência de Montevidéu marcou a consolidação do prestígio de Prebisch. Segundo Santa Cruz (1985), algumas delegações de países-membros presentes em Montevidéu convenceram David Owen que "era indispensável" que Prebisch assumisse a direção da CEPAL. Assim, no término da Conferência, David Owen acompanhou Prebisch até a sede central da ONU, em Nova York, onde Trygve Lie nomeou Prebisch Secretário Executivo da CEPAL.

No novo cargo, Prebisch logo deu início à preparação dos estudos para serem apresentados na Conferência do México de 1951, sempre no sentido de clarear e fundamentar melhor as teses apresentadas nas duas conferências anteriores. $\mathrm{O}$ trabalho deste ano de estudo seria intitulado "Problemas teóricos e práticos do crescimento econômico".

$\mathrm{Na}$ Conferência no México, entre maio e junho de 1951, mais que os informes apresentados, Prebisch estava preocupado com a sobrevivência da Comissão. A CEPAL havia sido criada para um período de vigência de apenas três anos, e os representantes dos Estados Unidos estavam dispostos a liquidar a Comissão. Um acordo para prorrogar a vida da CEPAL estava difícil de ser fechado. Nenhum país queria bater de frente com a posição dos Estados Unidos. No dia decisivo da Conferência, Prebisch já dava como perdida a possibilidade de a CEPAL continuar a existir. Mas aí o imponderável aconteceu: o representante brasileiro veio apres-

\footnotetext{
${ }^{8} \mathrm{Na}$ opinião de Furtado (1985, p. 76), o “[...] constitui seguramente a mais importante tentativa feita por Prebisch, em sua longa vida criativa, para apresentar suas teses fundamentais”.
} 
sado falar com Prebisch. Trazia um papel na mão. Era um telegrama do presidente Getúlio Vargas: "Salvem a CEPAL, custe o que custar". Com a posição firme do Brasil, outros países se uniram contra a ideia norte-americana, e a CEPAL tornou-se uma instituição permanente da ONU.

Para agradecer o apoio de Vargas à CEPAL, Prebisch pediu uma audiência com o presidente da República. Foi recebido no Palácio do Catete (Rio de Janeiro), acompanhado por Celso Furtado. Diz Prebisch que foi uma das melhores conversas que teve em sua vida. Vargas deu uma explicação clara e contundente de seu apoio à CEPAL. Referiu-se ao sentido de independência da América Latina e que havia chegado a hora de pensar com nossa própria mente. Furtado também ficou muito impressionado pela atitude e palavras do presidente. Segundo Furtado, Vargas havia sido o homem da industrialização, aos trancos e barrancos, lutando contra a "boa doutrina" dos mestres da época. Com a exposição que lhe fez Prebisch, ouvia uma demonstração lapidar de que havia feito a coisa certa, interessando-se em ter cópias dos trabalhados da CEPAL (Furtado, 1985).

Em relação aos aspectos teóricos, os três primeiros textos de Prebisch escritos para a Comissão marcaram o início do que ficou conhecido, posteriormente, como "o pensamento da CEPAL". O sistema centro-periferia seria o conceito mais difundido. Entende-se por Centro os países desenvolvidos, exportadores de bens manufaturados, e por Periferia os países em desenvolvimento ou subdesenvolvidos, exportadores de produtos primários. A América Latina pertencia à periferia da economia mundial. Para justificar a industrialização da região, que já vinha se realizando desde a Grande Depressão dos anos 1930, Prebisch questionava a validade da divisão internacional do trabalho. Segundo esta, o progresso técnico dos centros se distribuiria para a periferia pela baixa nos preços dos produtos manufaturados exportados (em razão do aumento de sua produtividade). Desta maneira, os produtos primários exportados da periferia, de menor produtividade, teriam um maior poder de compra, conforme evoluísse a técnica nos centros, não cabendo a industrialização da periferia do sistema (Prebisch, 1949, 1950, 1951).

Prebisch desmente este pressuposto da distribuição do progresso técnico, afirmando que, desde o final do século XIX, os preços dos produtos primários vinham se deteriorando em relação aos preços dos produtos manufaturados dos centros. Ou seja, por não terem sido repassados os aumentos de produtividade na baixa dos preços, o progresso técnico tinha se concentrado nos centros. Esta deterioração era explicada pelo movimento cíclico da economia. $\mathrm{Na}$ fase descendente do ciclo, a queda nos preços dos produtos primários exportados era maior do que a sua elevação na fase ascendente. Enquanto isso, os preços dos produtos manufaturados produzidos nos centros resistiam à queda. A rigidez dos preços manufaturados e a flexibilidade dos preços primários tinham como razão o maior poder sindical dos trabalhadores dos centros, que elevavam os salários na fase ascendente e mantinha-os na fase descendente (Ibid.).

A deterioração dos termos de intercâmbio e o próprio processo de industrialização (que necessitava de importações) eram os motivos, apontados por Prebisch, que levavam os países periféricos a desequilíbrios em seus balanços de pagamen- 
tos. Creditava, contudo, a grande culpa do desequilíbrio ao baixo coeficiente de importações dos Estados Unidos. Esta explicação para o desequilíbrio externo, datada de 1949, foi mantida no texto de 1950; porém, no texto de 1951, Prebisch acrescentou um novo fator causador do desequilíbrio: a elasticidade-renda da demanda. Ou seja, à medida que crescia a renda, diminuía a demanda relativa por bens primários e aumentava a demanda relativa por bens industriais (Ibid.) ${ }^{9}$.

Para atacar o desequilíbrio externo, Prebisch não via outro caminho senão a industrialização da América Latina, através do "processo de substituições de importações”. Observava, entretanto, que a industrialização da América Latina possuía dois sérios limites: a pequena escala de produção e a baixa poupança interna para inversões (Ibid. $)^{10}$.

Outro momento importante de Prebisch na CEPAL foi a Reunião Extraordinária da OEA (Organização dos Estados Americanos), realizada na cidade de Petrópolis, em novembro de 1954. A OEA pediu que a CEPAL preparasse um informe para apresentar na reunião. O informe escrito por Prebisch, intitulado "A cooperação internacional na política de desenvolvimento latino-americana”, preconizava uma política de industrialização e a necessidade de uma cooperação econômica global para a América Latina, apoiando preços agrícolas e planos de desenvolvimento. Assentavam-se as ideias do planejamento econômico, da industrialização, dos acordos de produtos, da reforma agrária, da cooperação técnica, além da criação de um banco de desenvolvimento latino-americano (Prebisch, 1954) ${ }^{11}$. Era um plano de ação. Cayuela (1988) considera a Reunião da OEA o "momento culminante da CEPAL" nesta sua primeira década; dali saíram as "ideias-força” para o desenvolvimento da América Latina.

As coisas estavam caminhando bem na CEPAL, mas, em setembro de 1955, um golpe militar retirou violentamente Perón da presidência da Argentina.

\footnotetext{
${ }^{9}$ Em entrevista de maio de 1985, Prebisch afirmou que a restrição do setor externo era o principal obstáculo ao desenvolvimento da América Latina. Por isso, seus estudos tinham como base o problema do balanço de pagamentos: "Tivemos que industrializar a Argentina sem construir antes uma teoria, porque necessitávamos proporcionar mais bens à população. Porém, não podíamos pagar todos os bens importados, pela queda de nossas exportações e a deterioração de nossa relação de preços de intercâmbio. Este é um fato simples. Sem nenhuma teoria, toda a América Latina fez o mesmo. Do México para baixo. Então, em meus dias de tranquila meditação, depois que deixei o Banco Central, comecei a lucubrar teorias. Apareceu o conceito de centro e periferia e também o da industrialização" (Prebisch apud Pollock et al., 2001, p. 16). Em resumo, Prebisch criou uma teoria que justificava a industrialização da América Latina (Love, 1998).

${ }^{10}$ Foi a pequena escala das indústrias latino-americanas, em razão de seus estreitos mercados nacionais, o motivo que incentivou Prebisch a defender a criação de um mercado comum latino-americano desde o seu primeiro trabalho na CEPAL. Prebisch considerava o comércio exterior um dos elementos propulsores do desenvolvimento econômico. A industrialização exigia novas importações de bens de capital e insumos que, para pagá-los, necessitava de exportações.

${ }^{11}$ A criação de um banco de desenvolvimento regional foi a questão prática mais debatida em Petrópolis. Assim, baseado nas ideias de Prebisch e da CEPAL, foi fundado, em 1959, o Banco Interamericano de Desenvolvimento (BID), que, além de financiar projetos de investimentos na região, prestava serviços de assistência técnica e pesquisa.
} 
Prebisch, então, aceitou o convite para colaborar com a nova junta militar, conservando, porém, o estatuto de funcionário internacional. Entre outubro de 1955 e abril de 1956, como assessor econômico do governo provisório, Prebisch redigiu as diretrizes do "Plano para a Recuperação Nacional".

Nos anos que seguem, Prebisch vai moldando a CEPAL e seus cursos de capacitação técnica (na área de desenvolvimento econômico). Sua principal tarefa, na segunda metade dos anos 1950, foi a constituição de um mercado comum entre os países da América Latina. O ponto inicial foi a criação da Comissão de Comércio da CEPAL, em setembro de 1955. A ideia de criar um mercado comum latino-americano surgiu para Prebisch como consequência da necessidade de intensificar o intercâmbio industrial entre os países latinos. Muitos de seus estudos invocavam a necessidade de uma integração comercial regional, principalmente o texto de 1959 , intitulado "O mercado comum latino-americano" (Prebisch, 1959). No entanto, as discussões chegaram a algo mais modesto: uma zona de livre comércio. Assim, pelo Tratado de Montevidéu, de fevereiro de 1960, criou-se a Associação Latino-Americana de Livre Comércio (ALALC), que começou a funcionar a partir de junho de 1961. A ALAC não era o que Prebisch desejava, mas o que foi possível realizar.

No início da década de 1960, um fato importante nos Estados Unidos movimentou as ações na América Latina: tratou-se da posse do novo presidente dos Estados Unidos, John F. Kennedy (janeiro de 1961). Ainda em sua campanha presidencial, em outubro de 1960, Kennedy afirmou que os Estados Unidos e a América Latina deveriam se unir numa "Aliança". Depois da posse de Kennedy, no dia 13 de março de 1961, numa recepção aos embaixadores latino-americanos na Casa Branca, e com a presença de Prebisch, o presidente Kennedy fez o discurso oficial propondo uma vigorosa ajuda ao desenvolvimento dos países latino-americanos. Estava lançada a "Aliança para o Progresso"12.

Ainda em 1961, Prebisch foi chamado a Nova York, onde lhe foi oferecido recursos para a criação de um instituto de planejamento sob a égide da CEPAL. Prebisch decidiu, então, deixar a Secretaria Executiva da CEPAL e dedicar-se exclusivamente a esta nova instituição. A ONU designou Prebisch como Diretor-Geral do Instituto Latino-Americano de Planejamento Econômico e Social (ILPES) em maio de 1962, mas ele teve que continuar também exercendo o cargo de secre-

\footnotetext{
${ }^{12}$ Foi durante a reunião do Conselho Interamericano Econômico e Social da OEA, realizada em Punta del Este (Uruguai), em agosto de 1961, que a proposta de Kennedy foi colocada no papel. Com a presença do Secretário de Estado dos Estados Unidos, Dean Rusk, o plano ficou registrado na famosa Carta de Punta del Este, criando oficialmente a Aliança para o Progresso. Segundo Cayuela (1988), Prebisch foi o principal elaborador da Carta de Punta del Este. Nela estava inserido as ideias-força lançadas na Reunião de Quitandinha, em 1954. Além disso, junto com a Aliança criou-se o Comitê Interamericano de Desenvolvimento Agrícola (CIDA) e o Instituto Interamericano de Ciências Agrícolas (IICA). O entusiasmo com a criação da Aliança para o Progresso contaminou todos, mas poucas iniciativas saíram do papel. Prebisch trabalhou como "coordenador" do painel de especialistas da Aliança, em Washington, entre janeiro e junho de 1962, mas se demitiu diante do insucesso do projeto. Com o assassinato de Kennedy, em 22 de novembro de 1963, terminou também a "força" da Aliança.
} 
tário na CEPAL até maio de 1963, quando da chegada do novo Secretário Executivo $^{13}$. Segundo Furtado (1985), nesta primeira década da CEPAL, a imagem da instituição não se diferenciava da imagem de Prebisch para muitos países da América Latina ${ }^{14}$.

Também em 1963, Prebisch publicou o livro Dinâmica do desenvolvimento latino-americano, que ampliou o sistema teórico centro-periferia com o conceito de "insuficiência dinâmica". A insuficiência dinâmica da economia era a incapacidade do sistema de absorver o crescimento da população ativa e a desocupação provocada pelo progresso técnico. Admitia ainda o "fim da etapa fácil de substituição de importações": havia sido relativamente simples substituir bens de consumo corrente e alguns duradouros, mas agora era vez de substituir bens de capital e intermediários, de fabricação mais complexa, que exigiam maiores mercados e capitais. A industrialização continuava sendo o caminho para o desenvolvimento. Segundo Prebisch (1963), o desenvolvimento econômico não viria de forma espontânea e sim de um esforço racional e deliberado, em que a acumulação de capital e a redistribuição da renda não se dariam pelo livre jogo do mercado, mas somente com uma grande participação do Estado sobre a poupança, a terra e a iniciativa individual, dando dinâmica ao sistema econômico.

$\mathrm{Na}$ avaliação de Prebisch (1963), ainda contida no livro Dinâmica do desenvolvimento, a acumulação de capital era o problema primordial do desenvolvimento latino-americano. Além de reduzir o consumo das classes de altas rendas e os gastos militares para fomentar a poupança interna, era ainda necessário recursos externos para transformar esta poupança em capacidade para importar bens de capital. Na sua visão, a concentração da renda e da riqueza na América Latina tinha como causa fundamental o privilégio ao acesso da terra. Por isso, a reforma agrária se fazia inadiável.

\footnotetext{
${ }^{13}$ Prebisch afirma que queria voltar a ensinar e que na CEPAL não havia podido fazer nada neste sentido. Segundo Cayuela (1988), Prebisch havia obtido recursos do BID e da PNUD (Programa das Nações Unidas para o Desenvolvimento) e assim apresentou no oitavo período de sessões da CEPAL, em fevereiro de 1962, a criação do ILPES. O Instituto teria duas funções principais: a) prestar serviços de capacitação e assessoramento aos países da região; b) realizar pesquisas sobre técnicas de planificação. O ILPES iniciou suas atividades oficialmente em 2 de julho de 1962, ao inaugurar o curso de Capacitação em Desenvolvimento Econômico, em Santiago.

${ }^{14}$ Para Cayuela (1988, p. 26-27), “Ainda que Prebisch não tenha sido o primeiro Secretário Executivo da CEPAL, sua personalidade e suas propostas teóricas marcaram a instituição desde o início [...] Suas ideias inspiraram uma geração inteira de economistas jovens, que encontraram em Prebisch um maestro e um catalisador capaz de sintetizar suas próprias ideias e experiências". Segundo Furtado (1985), foi no Brasil e no Chile que germinaram as ideias plantadas por Prebisch nesta fase. De acordo com Santa Cruz (1985, p. 40), "Sem desconhecer a contribuição dos brilhantes economistas e sociólogos que o secundaram, não se pode negar o fato de que a CEPAL ficou conhecida por muitos anos, com plena justificativa, como a CEPAL de Prebisch". O próprio Prebisch admite sua importância: “[...] creio ser responsável pela maior parte dos trabalhados que se tem feito na CEPAL, claro que com um esforço muito grande" (Prebisch apud Magariños, 1991, p. 153).
} 
No início de 1963, enquanto ainda dirigia a CEPAL e o ILPES conjuntamente, o Secretário-Geral da ONU, U Thant, ofereceu a Prebisch um novo desafio: organizar a primeira Conferência da UNCTAD (Conferência das Nações Unidas sobre Comércio e Desenvolvimento). Ao aceitar a tarefa, U Thant nomeou Prebisch Secretário-Geral da UNCTAD, em janeiro de 1963. Partiu, então, para Nova York para organizar o que seria o maior evento internacional da história até aquele momento.

A UNCTAD havia sido criada, em dezembro de 1962, pela Assembleia Geral das Nações Unidas, por solicitação dos países em desenvolvimento, que enxergavam desvantagens de seus produtos no comércio internacional. Segundo Bello (2000), a UNCTAD tinha três objetivos: a estabilização dos preços das commodities exportadas pelos países em desenvolvimento; tarifas preferências para os produtos dos mesmos países; ajuda financeira externa para contrabalancear as oscilações de preços das commodities.

$\mathrm{Na}$ reunião preparatória da Conferência, realizada entre maio e junho de 1963, em Genebra, criou-se o chamado Grupo dos 77, formado por países em desenvolvimento da América Latina, Ásia e África. O entendimento era que, sozinhos, os países em desenvolvimento não tinham nenhum poder nas negociações comerciais, mas, juntos, poderiam pleitear mais ajuda dos países industrializados nos organismos internacionais.

A Conferência da UNCTAD se realizou no Palácio das Nações, em Genebra, entre março e junho de 1964. Na abertura da Conferência, Prebisch apresentou o informe "Nova política comercial para o desenvolvimento", que defendia uma "nova política comercial" em prol do desenvolvimento econômico, que visava evitar o seu estrangulamento externo. A substituição de importações deveria atingir o frete (através de uma frota marítima própria) e os seguros, posto que estes dois elementos constituíam um déficit virtual no balanço de pagamentos. No entanto, advertia que o desenvolvimento econômico deveria ser buscado tanto no mercado interno como no mercado externo. Estes dois mercados não eram excludentes entre si. Dessa forma, a substituição de importações deveria ser conjunta com uma política de exportações industriais (Prebisch, 1964) ${ }^{15}$.

Estavam presentes, em Genebra, 4 mil delegados de 119 países. Foi um embate entre os países em desenvolvimento (G-77) e os países industrializados em relação ao comércio internacional. Perto do final da Conferência, Prebisch conseguiu um acordo com o G-77 para tornar a UNCTAD permanente. A "Declaração Conjunta dos Setenta e Sete Países em Desenvolvimento”, em 15 de junho de 1964, em prol da UNCTAD, marcou, com certo sucesso, o final da Conferência.

\footnotetext{
${ }^{15}$ Para o próprio Prebisch (1983, p. 1086), “Esta nova responsabilidade resultou muito pesada, porém, ao mesmo tempo, muito estimulante. Não tinha tempo para as lucubrações teóricas, de modo que tive de recorrer às minhas ideias da época da CEPAL".
} 
A Resolução n. 1995 da ONU, de 30 de dezembro de 1964, tornou a UNCTAD um órgão permanente das Nações Unidas, com sede em Genebra. Em 10 de fevereiro de 1965, Prebisch (aos 63 anos) recebeu a nomeação para Secretário-Geral da instituição pela Assembleia Geral da ONU.

Residindo em Genebra, Prebisch, então, tratou de organizar a segunda conferência da UNCTAD, fazendo uma peregrinação pelos países dos cinco continentes. A II UNCTAD foi realizada em Nova Delhi (Índia), entre fevereiro e março de 1968, com a presença de 1.600 delegados de 131 países. Na abertura da Conferência, Prebisch apresentou o informe "Para uma estratégia global de desenvolvimento". O objetivo da estratégia era resolver os problemas que impediam acelerar o ritmo de desenvolvimento econômico e social. Os problemas eram: desequilíbrio externo, déficit de poupança e vulnerabilidade externa (Prebisch, 1968). Porém, as negociações entre o G-77 e os países industrializados não caminharam bem. No final de março, com poucos resultados concretos, a II UNCTAD foi encerrada num clima de fracasso ${ }^{16}$.

Frustrado com a falta de ações práticas durante a II UNCTAD, e com problemas de saúde, Prebisch entregou sua carta de demissão ao Secretário-Geral da ONU, em novembro de 1968. Estava com 67 anos. Sua saída oficial da UNCTAD ocorreu em março de 1969. Segundo Magariños (1991, p. 12), Prebisch "abandonou" a Conferência "[...] diante da evidência da impossibilidade de fazer do organismo o instrumento de regeneração política, econômica e social com que sonhava".

No início de 1969, Prebisch fixou residência em Washington para chefiar a comissão de desenvolvimento do Banco Interamericano de Desenvolvimento (BID). O objetivo da comissão era preparar um documento para apresentação na reunião do BID, programada para abril de 1970. Mesmo trabalhando em Washington, Prebisch ainda continuava exercendo o cargo de Diretor-Geral do ILPES. Nas palavras de Dosman (2010, p. 502), nesta época, Prebisch “[...] era uma das personalidades latino-americanas mais reconhecidas no mundo" ${ }^{17}$.

Depois de mais de um ano de trabalho, o "Relatório Prebisch" foi apresentado na reunião do BID, em Punta del Este (Uruguai), em abril de 1970. Intitulado "Transformação e desenvolvimento: a grande tarefa da América Latina", o relatório, segundo o próprio Prebisch, era voltado para a ação. Fundamentava suas observações sobre uma sólida base de dados, que possibilitava afirmar, entre outras coisas, que os países latino-americanos que não tiveram problemas de balanço de

\footnotetext{
${ }^{16}$ Para saber o que representava a UNCTAD para a época, escreveu Magariños (1991, p. 23): “A UNCTAD despertou uma imensa esperança de que se produziria uma mudança total na orientação e nas atividades dos países ricos e poderosos no manejo do comércio e da vida econômica mundial”. Após a II UNCTAD, estas esperanças se mostraram frustradas. Para Magariños, a UNCTAD foi a projeção mundial das ideias de Prebisch, formuladas e polidas durante seus anos na CEPAL.

${ }^{17}$ Não foi à toa que o economista sueco Gunnar Myrdal indicou Raúl Prebisch para receber o primeiro Prêmio Nobel de Economia, dado pelo Banco Central da Suécia, em 1969. No entanto, os vencedores foram Jan Tinbergen e Ragnar Frisch.
} 
pagamentos foram os que menos adotaram a política substitutiva de importações (Prebisch, 1970) $)^{18}$.

Prebisch havia prometido ao seu pessoal do ILPES, no início de 1969, que voltaria para Santiago após o término do relatório do BID. A proposta era revisar as antigas ideias da CEPAL. Em meados de 1971, Prebisch finalmente retornou ao ILPES, em Santiago. Seus esforços se voltaram para obter financiamentos para a sobrevivência do Instituto. Desgostoso com a situação, Prebisch pediu demissão em janeiro de 1973, aposentando-se das Nações Unidas, aos 71 anos de idade. Para Dosman (2010, p. 462), o ILPES foi o maior fracasso de Prebisch: "Que modo de concluir sua carreira brilhante! O fundador do estruturalismo e criador da UNCTAD foi reduzido a lutar pela menor das siglas que criou: o ILPES"19.

De volta a Washington, o valor de sua aposentadoria da ONU não cobria todos os seus gastos. Dessa forma, Prebisch aceitou continuar na ONU, como assessor do Secretário-Geral para assuntos de desenvolvimento. Além disso, aceitou ser assessor do Secretário-Geral da OEA, entre 1973 e 1975.

\section{A REVISTA DE LA CEPAL E A ASSESSORIA PRESIDENCIAL}

Em agosto de 1975, Prebisch retornou à Santiago para um novo trabalho na CEPAL. Aos 74 anos, Prebisch aceitou o convite de Enrique Iglesias (Secretário Executivo) para dirigir uma nova publicação: a Revista de la CEPAL. No primeiro número da Revista, editada no segundo semestre de 1976, Prebisch publicou um longo artigo intitulado "Crítica ao capitalismo periférico" (Prebisch, 1976). Era o começo de novas ideias ${ }^{20}$.

Em 1977, ganhadores do Prêmio Nobel de Economia, como Tinbergen, Samuelson, Myrdal e Leontief, indicaram Prebisch ao famoso prêmio de economia. Mais uma vez, porém, seu nome foi preterido em favor de Berti Ohlin e James Meade.

\footnotetext{
${ }^{18}$ Neste relatório, Prebisch escreveu sobre Marx e o socialismo. Para ele, o socialismo real foi um método de desenvolvimento e não a transformação de uma economia avançada. Também foi neste texto que Prebisch iniciou a formulação de sua futura "Teoria da transformação", em que os fatos poderiam levar o Estado a socializar as grandes empresas. Prebisch criticava duramente o sistema capitalista, dizendo que qualquer sistema que não corrigisse a insuficiência dinâmica e não distribuísse equitativamente a sua renda, teria perdido a justificativa de se prolongar (Prebisch, 1970).

${ }^{19}$ Em março de 1973, Prebisch compareceu às comemorações do $25^{\circ}$ aniversário da CEPAL, na cidade de Quito (Equador). Na sua exposição, disse que não vacilava "[...] em dizer que a experiência da CEPAL, se bem tenha significado para mim muitos dissabores e muitas dificuldades, tem sido a tarefa que mais satisfações deram em minha vida" (Prebisch apud Cayuela, 1988, p. 15).

${ }^{20} \mathrm{Na}$ sequência, surgiram os artigos "Estrutura socioeconômica e crises do sistema" (Prebisch, 1978), "As teorias neoclássicas do liberalismo econômico" (Prebisch, 1979), "Para uma teoria da transformação" (Prebisch, 1980) e "A periferia latino-americana no sistema global do capitalismo" (Prebisch, 1981b). Segundo Prebisch (1983, p. 1087), longe de atribuições executivas, depois de muitos anos, pôde dedicar-se na revista a melhorar a sua interpretação do capitalismo periférico, indo além da teoria econômica.
} 
Depois dos longos artigos publicados na Revista de la CEPAL, entre $1976 \mathrm{e}$ 1981, Prebisch organizou estas ideias no livro "Capitalismo periférico: crise e transformação", de 1981. Buscava harmonizar a dinâmica do sistema econômico com o regime democrático, através de uma "Teoria da transformação". Seria uma síntese entre socialismo e liberalismo. Socialismo, enquanto o Estado regularia democraticamente a acumulação e a distribuição. Liberalismo, enquanto consagraria essencialmente a liberdade econômica do que produzir e do que consumir (Prebisch, 1981c) ${ }^{21}$.

Após esta fase de elaboração da Teoria da Transformação, Prebisch escreveu uma última série de artigos relativamente curtos (de 1981 a 1986), cuja preocupação girava em torno da inflação e da dívida externa dos países latino-americanos.

Em 1982, numa palestra no Banco Mundial, Prebisch apresentou o ensaio "Cinco etapas de meu pensamento sobre o desenvolvimento". Neste texto, Prebisch, aos 81 anos de idade, lembrou o passado e dividiu o seu pensamento sobre o desenvolvimento econômico em cinco etapas sucessivas, sob a influência de uma realidade que se transformava e dos ensinamentos de sua própria experiência (Prebisch, 1983). Trata-se de texto fundamental para compreensão de seu pensamento.

No final de 1983, surgiu o seu último grande desafio. Raúl Alfonsín assumia a presidência da Argentina, encerrando a ditadura militar no país (1976-1983). Alfonsín convidou Prebisch para ser assessor econômico da presidência e preparar um programa de reativação econômica. Aos 83 anos estava de novo no centro do furacão, negociando com o Congresso Nacional e lidando com a crítica imprensa argentina. Tratou pessoalmente da negociação da dívida externa do país com o FMI. Os anos de 1984 a 1986 foram, assim, de plena atividade, mas o fim estava próximo.

Em abril de 1986 Prebisch estava em Santiago, trabalhando na Revista de la CEPAL. Em sua casa de Cajón Del Maipo lia o romance de Isabel Allende, "A casa dos espíritos". Sua última frase foi "Que grande livro!" (Dosman, 2010). Na madrugada de 29 de abril seu coração parou de bater, vítima de um ataque cardíaco. Estava com 85 anos.

\section{CONCLUSÃO}

Em termos profissionais, a vida de Raúl Prebisch teve três fases bem distintas. A primeira, na órbita argentina, como funcionário público da administração direta

\footnotetext{
${ }^{21} \mathrm{O}$ novo livro também atacava as teorias neoclássicas por descartarem de seus raciocínios os elementos importantes da realidade social, política e cultural, bem como o desenvolvimento histórico das coletividades. Para Prebisch, os teóricos neoclássicos sistematizaram e desenvolveram seus raciocínios no vácuo, fora do tempo e do espaço. Sobre Milton Friedman, Prebisch afirmava que suas ideias não eram novas, mas sim uma divulgação inteligente do pensamento marginalista do século XIX. A grande divulgação, até certo ponto deliberada, das ideias neoclássicas respondia, em grande parte, ao jogo de interesses (Prebisch, 1981c).
} 
e professor universitário. $\mathrm{Na}$ segunda fase, como servidor das Nações Unidas (no sistema CEPAL-ILPES), tratou das questões econômicas da América Latina. Por fim, a terceira fase, na Secretaria-Geral da UNCTAD, trabalhou com os problemas dos países subdesenvolvidos de todo o planeta.

Não resta dúvida, nos dias de hoje, de que Raúl Prebisch foi o mais influente economista nascido na América Latina. Cargos não lhe faltaram. Desafios também não. Enquanto trilhava suas funções públicas, Prebisch foi interpretando teoricamente o mundo em que vivia. Nasceu, assim, o sistema teórico centro-periferia, que incluía o crescimento para dentro e para fora, a deterioração dos termos de intercâmbio, a luta pela industrialização através da substituição de importações, a necessidade de um mercado comum e também de um banco de financiamento ao desenvolvimento, entre muitas outras ideias e sugestões.

Ao longo das décadas, Prebisch nunca abandonou o seu sistema teórico centro-periferia. Reconhecia que a polêmica sobre a dependência, na década de 1960, enriqueceu este sistema. A contribuição mais importante, segundo Prebisch, foi a incorporação das relações de poder nesta análise. Para ele, o sistema centro-periferia não tinha o desígnio de se tornar uma teoria própria, diferente do pensamento dos centros, apenas requeria que os fenômenos do capitalismo periférico se inserissem em uma teoria global do desenvolvimento capitalista. Quanto à industrialização, dizia que a substituição de importações não era estática, pois a diversificação da demanda impunha substituir novos produtos. Até o seu último texto, Prebisch (1986) continuava acreditando na substituição de importações e nas exportações de manufaturas como forma de superar o desequilíbrio externo, o "grande inimigo" dos países latino-americanos.

\section{REFERÊNCIAS BIBLIOGRÁFICAS}

Bello, W. (2000) "UNCTAD: time to lead, time to challenge the WTO”, Focus on Trade, n.44.

Cattaneo, C. (1991) "Prebisch y las relaciones agriculture-industria”, Revista de la CEPAL, n. 43, abril, pp. 151-166.

Cayuela, J. (1988) CEPAL 40 anos (1948-1988). Santiago de Chile: CEPAL.

CEPAL. (1969) El pensamiento de la CEPAL. Santiago de Chile: Editorial Universitaria.

Dosman, E. J. (2001) “Los mercados y o Estado en la evolución del manifesto de Prebisch", Revista de la CEPAL, n.75, diciembre, pp. 89-105.

Dosman, E. J. (Org.). (2006) Raúl Prebisch: El poder, los princípios y la ética para el desarrollo. Buenos Aires: IDB/INTAL.

Dosman, E. J. (2010 [2011]) Raúl Prebisch (1901-1986): A Construção da América Latina e do Terceiro Mundo. Rio de Janeiro: Contraponto/Centro Internacional Celso Furtado.

Floto, E. (1989) "El sistema centro-periferia y el intercambio desigual", Revista de la CEPAL, Santiago de Chile, n. 39, diciembre, pp. 147-167.

Furtado, C. (1985) A fantasia organizada. Rio de Janeiro: Paz e Terra.

González, N.; Pollock, D. (1991) "Del ortodoxo al conservador ilustrado: Raúl Prebisch em la Argentina, 1923-1943”, Desarrollo Económico, vol.30, n.120, pp.455-486.

Gurrieri, A. (1982) “La economia política de Raúl Prebisch”. In: Gurrieri, A. (Org). La obra de Prebisch en la CEPAL. México: Fondo de Cultura Económica.

Gurrieri. A. (2001) “Las ideas del joven Prebisch”, Revista de la CEPAL, n. 75, diciembre, pp. 69-82. 
Hirschman, A. (1961) "Ideologies of economic development in Latin America". In: Hirschman, A. (Org.). Latin American Issues: essays and comments. New York: The Twentieth Century Fund.

Hodara, J. (1987) Prebisch y la CEPAL: substancia, trayectoria y contexto institucional. Cidade do México: Colegio de México.

Keynes, J. M. (1936 [1985]) A Teoria Geral do Emprego, do Juro e da Moeda. Sao Paulo: Nova Cultural.

Love, J. (1998) A construção do tefceio mundo. São Paulo: Terra e Paz.

Magariños, M. (1991) Diálogos con Raúl Prebisch. México: Fondo de Cultura Económica.

Ocampo, J. A. (2001) "Raúl Prebisch y la agenda del desarrollo en los albores del siglo XXI", Revista de la Cepal, n. 75, diciembre, pp. 25-40.

Pedrão. F. C. (Org.). (1988) O pensamento da CEPAL. Salvador: OEA/UFBA/Ianamá.

Pedrão, F. C. (2010) A passagem de Prebisch. Disponível em: <http://pedraopedrao.blogspot.com.br/>. Acesso em: 11 nov. 2015.

Pollock, D.; Kerner, D.; Love, J. (2001) “Entrevista inédita a Prebisch: logros y deficiencias de la CEPAL”, Revista de la Cepal, n.75, diciembre, pp.09-23.

Pollock, D.; Kerner, D.; Love, J. (2006) “Prebisch en la UNCTAD”. In: Dosman, E. (Org.). Raúl Prebisch: el poder, los princípios y la ética para el desarrollo. Buenos Aires: IDB/INTAL.

Prebisch. R. (1944a) “Observaciones sobre los planes monetarios internacionais”, El Trimestre Económico, vol.11, n.42, julio-septiembre, pp.185-208.

Prebisch, R. (1944b) "El patrón oro y la vulnerabilidad económica de nuestros países", Revista de Ciencias Económicas, série 02, n.272, marzo, pp.211-235.

Prebisch, R, (1947 [1991]) Keynes: uma introdução. São Paulo: Ed. Brasiliense.

Prebisch, R. (1949 [1982]) "El desarrollo económico de la América Latina y algunos de sus principales problemas”. In: Gurrieri, A. La obra de Prebisch en la CEPAL. México: Fondo de Cultura Económica.

Prebisch, R. (1950 [1982]) "Crecimiento, desequilibrio y disparidades: Interpretación del proceso de desarrollo económico”. In: Gurrieri, A. La obra de Prebisch en la CEPAL. México: Fondo de Cultura Económica.

Prebisch, R. (1951 [1982]) “Problemas teóricos y prácticos del crecimiento económico”. In: Gurrieri, A. La obra de Prebisch en la CEPAL. México: Fondo de Cultura Económica.

Prebisch, R. (1954 [1982]) “La cooperación internacional en la política de desarrollo latinoamericana”. In: Gurrieri, A. La obra de Prebisch en la CEPAL. México: Fondo de Cultura Económica.

Prebisch, R. (1959 [1982]) “El mercado común latinoamericano”. In: Gurrieri, A. La obra de Prebisch en la CEPAL. México: Fondo de Cultura Económica.

Prebisch, R. (1963 [1968]) Dinâmica do desenvolvimento latino-americano. Rio de Janeiro: Fundo de Cultura.

Prebisch, R. (1964) Nueva política comercial para el desarrollo. México: Fondo de Cultura Económica.

Prebisch, R. (1968 [1982]) "Hacia una estrategia global del desarrollo". In: Gurrieri, A. La obra de Prebisch en la CEPAL. México: Fondo de Cultura Económica.

Prebisch, R. (1970 [1973]) Transformações e desenvolvimento: a grande tarefa da América Latina. Rio de Janeiro: Fundação Getúlio Vargas.

Prebisch, R. (1972) La creación del Banco Central y la experiência monetária argentina entre los años 1935-1943. Buenos Aires: BCRA.

Prebisch, R. (1976) “Crítica al capitalismo periférico”, Revista de la CEPAL, n.1, primer semestre, pp. 7-74.

Prebisch, R. (1978) “Estructura socioeconómica y crisis del sistema”, Revista de la CEPAL, n.6, segundo semestre, 167-264.

Prebisch, R. (1979) "Las teorias neoclásicas del liberalismo econômico”, Revista de la CEPAL, , n.7, abril, pp. 167-188.

Prebisch, R. (1980) "Hacia una teoría de la transformación”, Revista de la CEPAL, n.10, abril, pp. 165-216. 
Prebisch, R. (1981a) "Prefácio”. In: Rodríguez, O. Teoria do subdesenvolvimento da Cepal. Rio de Janeiro: Ed. Forense-Universitária.

Prebisch, R. (1981b) “La periferia latinoamericana en el sistema global del capitalismo", Revista de la CEPAL, n.13, abril.

Prebisch, R. (1981c 1987]) Capitalismo periférico: crisis y trasformación. México: Fondo de Cultura Económica.

Prebisch, R. (1983) “Cinco etapas de mi pensamiento sobre el desarrollo”, El Trimestre Económico, vol.50, n.198, abril-junio, pp.1077-1096.

Prebisch, R. (1986) "Exposición (...) en el vigesimoprimer período de sesiones de la CEPAL", Revista de la Cepal, n.29, agosto, pp.13-16.

Rodríguez, O. (1981) Teoria do subdesenvolvimento da CEPAL. Rio de Janeiro: Forense Universitária.

Rodríguez, O. (2001) "Prebisch: actualidad de sus ideas básicas", Revista de la CEPAL, n. 75, diciembre, pp. 41-52.

Rodríguez, O. (2006 [2009]) O estruturalismo latino-americano. Rio de Janeiro: Civilização Brasileira.

Salazar, J. M. (1993) "El resurgimiento de la integración y el legado de Prebisch", Revista de la CEPAL, n. 50, agosto, pp. 21-40.

Santa Cruz, H. (1985) La CEPAL, encarnación de una esperanza de América Latina. Santiago de Chile: Naciones Unidas. (Cuadernos de la Cepal, n.50).

Singer, H. W. (1950) "The distribution of gains between investing and borrowing countries", American Economic Review, vol.XL, n.02, may, pp.473-485.

Solar, J. G. (2005) “Conversaciones con Raul Prebisch”. In: Mallorquín, C. Textos para el estúdio del pensamiento de Raúl Prebisch. Disponível em: <http://www.facso.uchile.cl/publicaciones/moebio/25/mallorquin.htm>. Acesso em: 12 nov. 2015.

Viner, J. (1952) International trade and economic development: lectures delivered at the National University of Brazil. Glencoe, Iii: Free Press. 